Institut of Nuclear Physics

EXPERIMENTS WITH UNDULATOR RADIATION OF A SINGLE ELECTRON

I. Mrajev, V.M. Popik, T.V. Shattan,

A.S. Gokolov, N.A. Vinokurov, P.Y. Vorobyov

BUDKERINP 93-73

NOVOSIBIRSK

1993 


\title{
Experiments with Undulator Radiation of a Single Electron
}

I.V. Pinayev, V.M. Popik, T.V. Shaftan,

A.S. Sokolov, N.A. Vinokurov, P.V. Vorobyov

Budker Institute of Nuclear Physics

11 Lavrentyev Ave., Novosibirsk, 630090, Russia

Tel: 7-(3832)-359012 Fax: 7-(3832)-352163

E-mail: pinayev@inp.nsk.su

\begin{abstract}
A single electron circulating in a storage ring is a very peculiar object. Permanent emission of synchrotron radiation offers the possibility to observe the electron but also causes the "natural bunch length". In the quasiclassical treatment electron position uncertainties arise from the averaging of the energy and position of the point-like electron over many turns in the storage ring. Nevertheless a question about the electron localization remains open. The radiation from a long undulator permits to obtain "snapshots" of the electron longitudinal distribution. The experiments with a single electron on VEPP-3 optical klystron are discussed.
\end{abstract}

@ Budker Institute of Nuclear Physics 
The well-known phenomenon of the "natural" energy spread and bunch length (and the corresponding horizontal emittance) in electron storage rings $[1,2]$ were fully investigated both theoretically and experimentally many years ago. According to the quasiclassical theory by Sands, Kolomensky and Lebedev $[3,4]$ the interaction of an electron with a radiation field is treated as statistically independent emission of photons. It causes small jumps of the electron energy and, consequently, the diffusion in the phase space. The natural energy spread (and the natural bunch length) is the result of the equilibrium of this diffusion and the radiation damping of synchrotron oscillations. From the point of view of the quantum theory, 
we have to consider the electron using approfriate density operator which leads us to a question about the particular amplitude and phase of the synchrotron oscillations of electron (i.e. the energy and the longitudinal coordinate inside the bunch). It should be notod that system is stationary and does not interact wilh any "thermostat", except an infinite set of field oscillators with zero energy, so it is "simple" and regular.

We have investigated the electron radiation with a view to obtain information about its state. We have taken advantage of two distinguished features of the VEPP-3 storage ring - its large bunch length and long undulator. The main parameters of the VEPP-3 storage ring are listed in Table 1. The undulator with 66 periods is installed at the straight line section [5].

Table 1

Perimeter

RF harmonic number

Energy

Relative natural energy spread, $\frac{\sigma_{E}}{E}$ Bunchlength $\sigma_{\mathrm{s}} @ \mathrm{U}_{\mathrm{RF}}=1.1 \mathrm{kV}$
$74,7 \mathrm{~m}$

$350 \mathrm{MeV}$

$3 \cdot 10^{-4}$

$0,9 \mathrm{~m}$

Layout of the experiment similar to the Brown-Twiss interferometer is shown on Figure 1. Light emitted by the electron in the undulator passes through the optical spatial 
Hter and the beamsplitter to two photomultipliers. Photocont pulses from each photomultiplier arrive at the amplitude discriminator-shapers (see Fig. 2). Puises from one of the photomultipliers give "start" to the circuit for the interval measurements and pulses from another - "stop". The coincidence circuit permits to registrate pulses which have the time interval between them less than 14 ns (the revolution period is 250 ns). The time dependence of the count rate of one photomultiplier is shown on Figure 3. One step (about $2 \mathrm{kHz}$ ) corresponds to the loss of one electron. The results of the Brown-Twiss experiment for the various number of circulating electrons are shown on Figure 4 . We switch on the Rl system on the 18th harmonics of the revolution frequetcy and decrease the bunchlength $\sigma_{s}$ to less than $5 \mathrm{~cm}$ to check the resolution of the system. The time distribution of the interval between the photocounts shown on Figure 5 demonstrates a 1.1 ns time resolution istandard deviation).

According to the well-known results of quantum optics [6], the probability of the photocount from the first photomultiplier turing the tine intervel from $t_{1}$ until $t_{1}+c t$, and photoconit from the second one from t until $\mathrm{t}_{2}+d \mathrm{t}_{2}$ is proportional to the second order corretation function of the incient light:

$w\left(t_{1}, t_{2}\right) d t_{1} d t_{2} \times g\left(\vec{r}, t_{1}: \vec{r}, t_{2} ; \vec{r}_{1}, t_{2}, \vec{r}, t_{1}\right) d t_{2} d t_{2},(i)$ 
where

$$
\begin{aligned}
G^{(2)}\left(\vec{r}_{1}, t_{1} ; \vec{r}_{2}, t_{2} ; \vec{r}_{3}, t_{3} ; \vec{r}_{4}, t_{4}\right)= \\
\quad=\operatorname{Sp}\left[\rho E^{-}\left(\vec{r}_{1} t_{1}\right) E^{-}\left(\vec{r}_{2}, t_{2}\right) E^{+}\left(\vec{r}_{3}, t_{3}\right) E^{+}\left(\vec{r}_{4}, t_{4}\right)\right]
\end{aligned}
$$

and $\mathrm{E}^{-}, \mathrm{E}^{+}$are the field operators, $\rho$ is the density matrix.

The probability of registration of two photocounts separated by the interval $\tau$ during the revolution period $T$ is equal to

$$
W(\tau)=\int_{-T / 2}^{T / 2} w\left(t_{1}, t_{1}+\tau\right) d t_{1}
$$

In our case the bunch length is much less than the perimeter and so we may choose the integration limits in the region where $w=0$. In the classical limit, for the radiation of $N$ uncorrelated electrons

$$
\begin{gathered}
W\left(t_{1}, t_{2}\right) \sim N\left[\delta\left(t_{1}-t_{2}\right) f\left(t_{2}\right)+(N-1) f\left(t_{1}\right) f\left(t_{2}\right)\right], \\
-c^{2} t^{2} / 2 \sigma^{2}
\end{gathered}
$$

$\left(f(t)=\frac{c}{\sqrt{2 \pi} \sigma_{s}} e^{s}\right.$ is the longitudinal distribution of electrons) and

$$
W(\tau) \sim N\left[\delta(\tau)+(N-1) \frac{c}{\sqrt{2 \pi \sigma_{s}}} e^{-c^{2} t^{2} / 2 \sigma^{2}} s\right] .
$$


If approximate the resolution curve of our measurement system (Figure 5) by the gaussian with standard deviation , we can derive the theoretical dependence, corresponding to the results, shown on Figure 4:

$$
\frac{c}{\sqrt{2 \pi \sigma_{r}}} e^{-\tau^{2} / 2 \sigma_{r}^{2}}+(N-1) \frac{c}{2 \sqrt{\pi\left(\sigma_{s}^{2}+c^{2} \sigma_{r}^{2}\right)}} e^{-\tau^{2} c^{2} / 4\left(\sigma_{s}^{2}+c^{2} \sigma_{r}^{2}\right)}
$$

Thus we can see a fairly good agreement of the results with the model of quasiclassical pointlike electrons.

We have also performed another experiment measuring the longtime correlation in the light intensity. We used one photomultiplier and put its signal to an RF spectrum analyzer whose resolution is $3 \mathrm{~Hz}$. Investigating the spectrum near the harmonics of the revolution frequency we have detected the sidebands corresponding to the synchrotron oscillations of a single electron (Figure 6). Their width was in agreement with the damping time of synchrotron oscillations.

The results of our experiments have showed that the electron behaves like the classical oscillator excited by quantum noise and probably is an interesting example of the appearance of the stochastic process in a regular quantum dynamical system. 


\section{REFERENCES}

[1] A.A. Kolomensky and A.N. Lebecev. "The theory of cyclic accelerators", Moscow, 1962.

[2] M.Sands, in: XLV? Corso, Enrico Fermi School, New York, Academic Press, 2971, p.257.

[3] M. Sands, Phys. Rev. 97 (1955) 470.

[4] A.A. Kolomensky and A.N. Lebedev, Doklady of Soviet Academy of Science 106 (1956) 87, Soviet JETP 30 (1956) 207, 1161.

[5] N.G. Gavrilov et al., Nucl. Instr. and Meth. A282 (1989) p. 422.

[6] R.J. Glauber, in: Quantum Optics and Electronics (Proceedings of Les Houches 1964 Summer Schoul), ed. C. De Witt, New York, 1955, p. 63. 


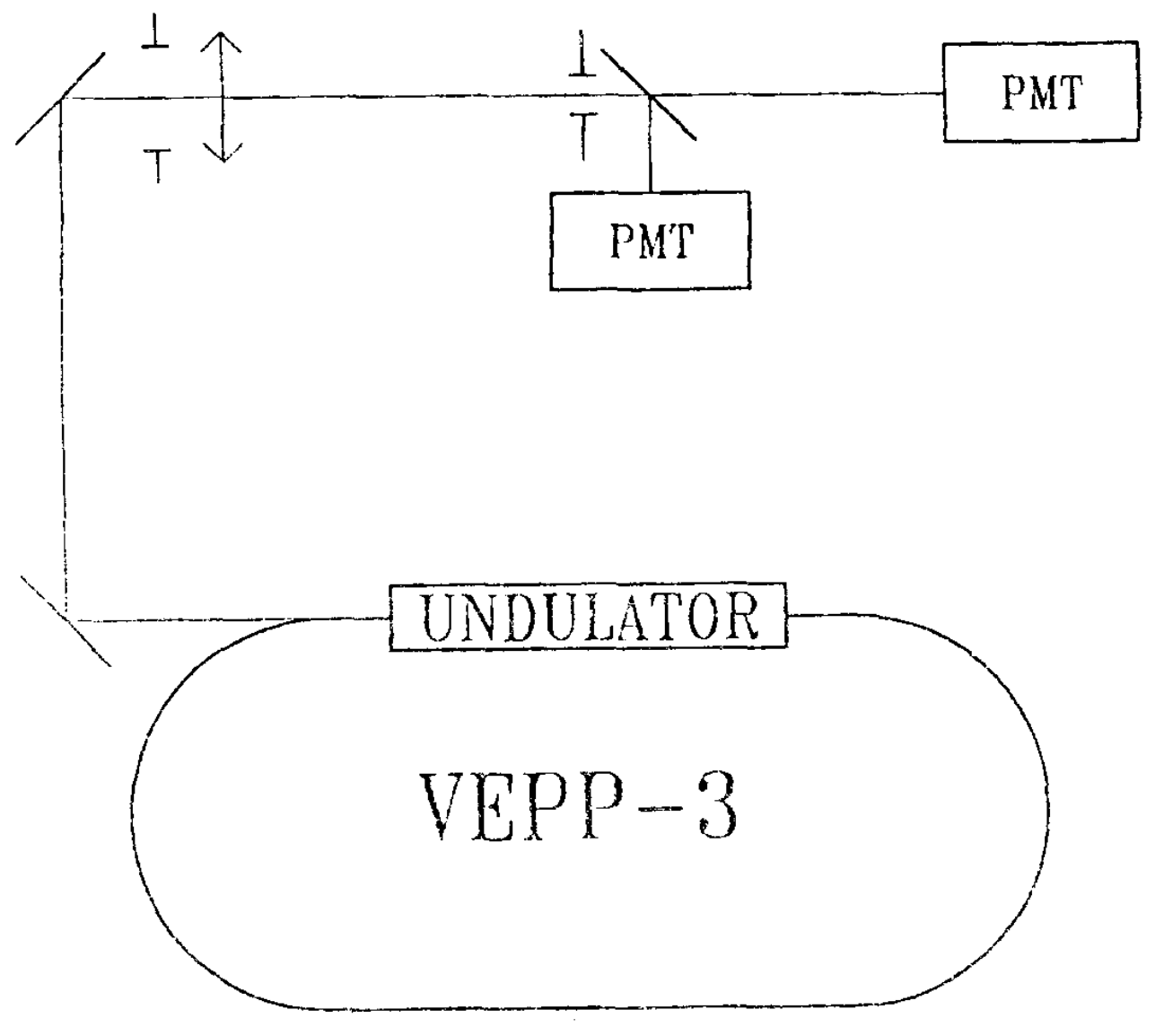

Fig. 1. Layout of the installation. 


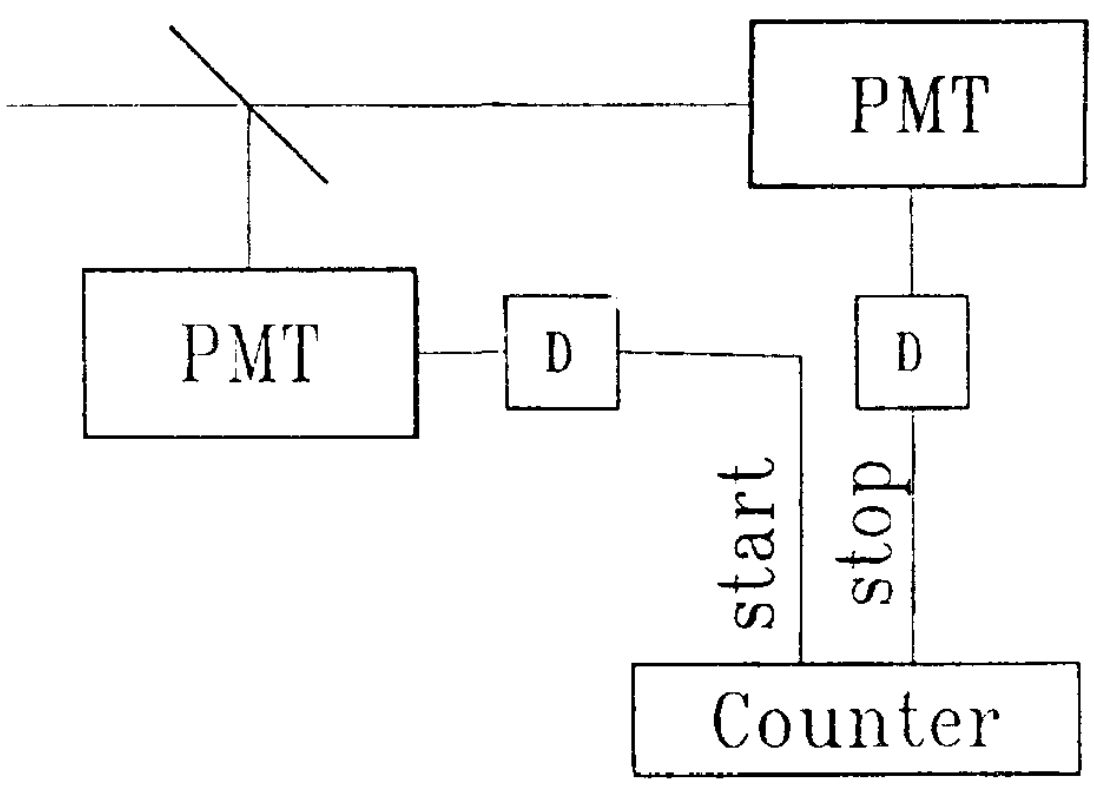

Fig. 2. Layout of the time interval measurements. 


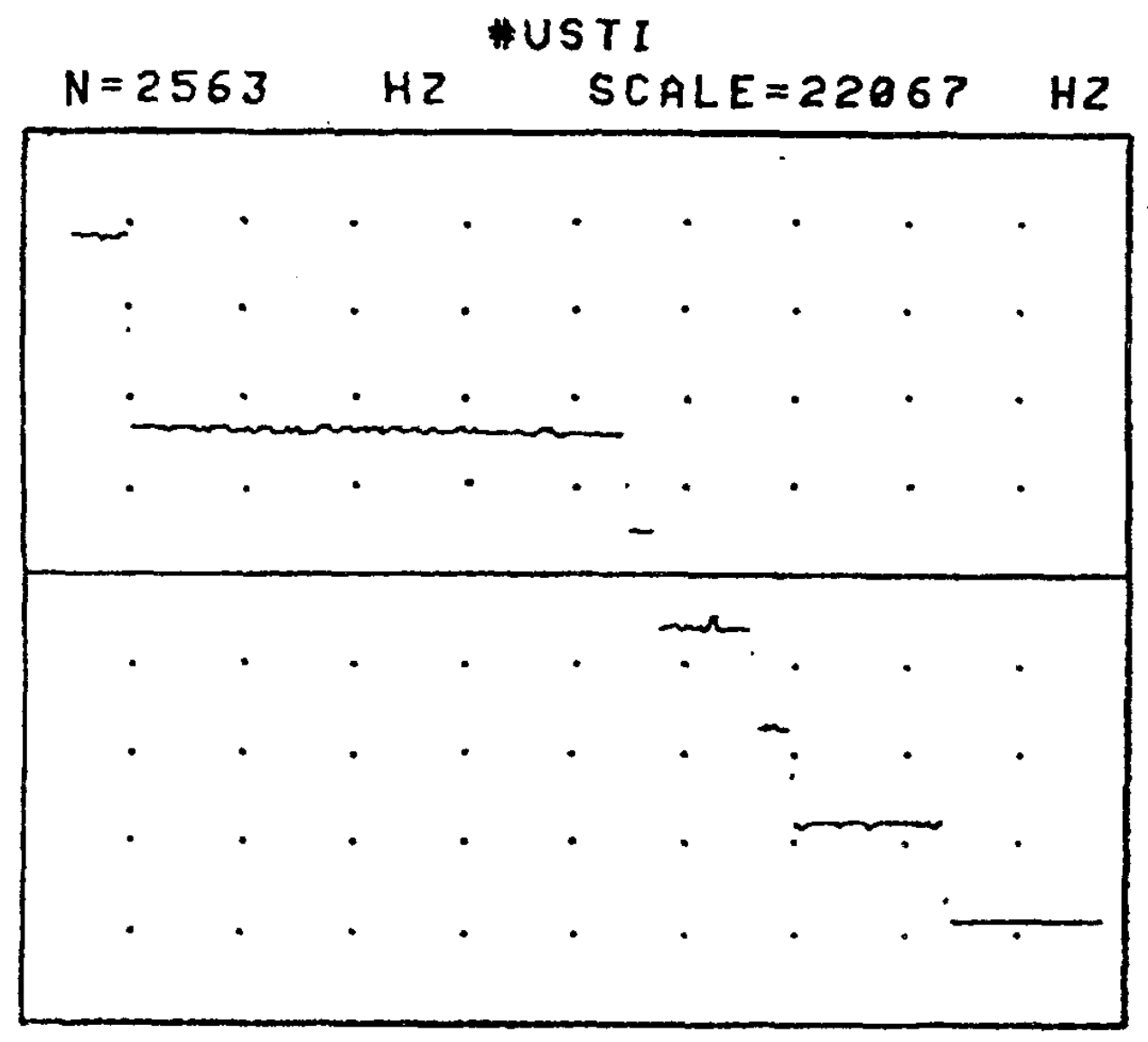

Fig. 3. The dependence of the counts rate from time. One step corresponds to the blow out of one electron. (Vertical scale is $22 \mathrm{kHz}$, horisontal scale is 2560 seconds). 
TIME $=88 \quad 5$

计获 $=373.6964$

EUENTS $=4794.26 ?$
$13 / 59 / 64$

$08,66 / 93$

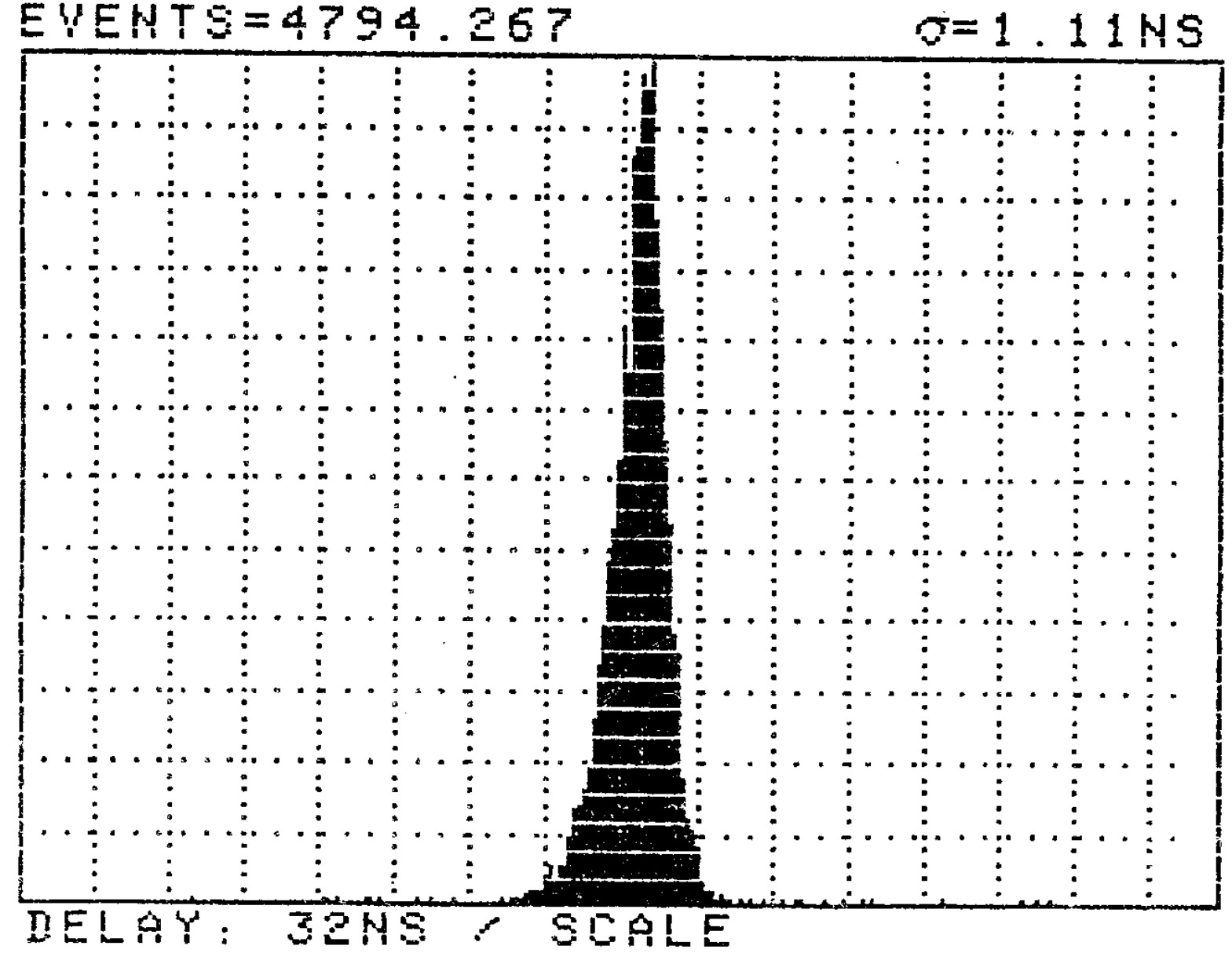

Fig.4. The dependance of the number of photocount pairs. pairsfrom time interval between photocounts. Number of electrons for upper left figure is approximately 20, for upper right - 4, for bottom left - 3, for bottom right one. Horizontal scale is 2 ns/div. 

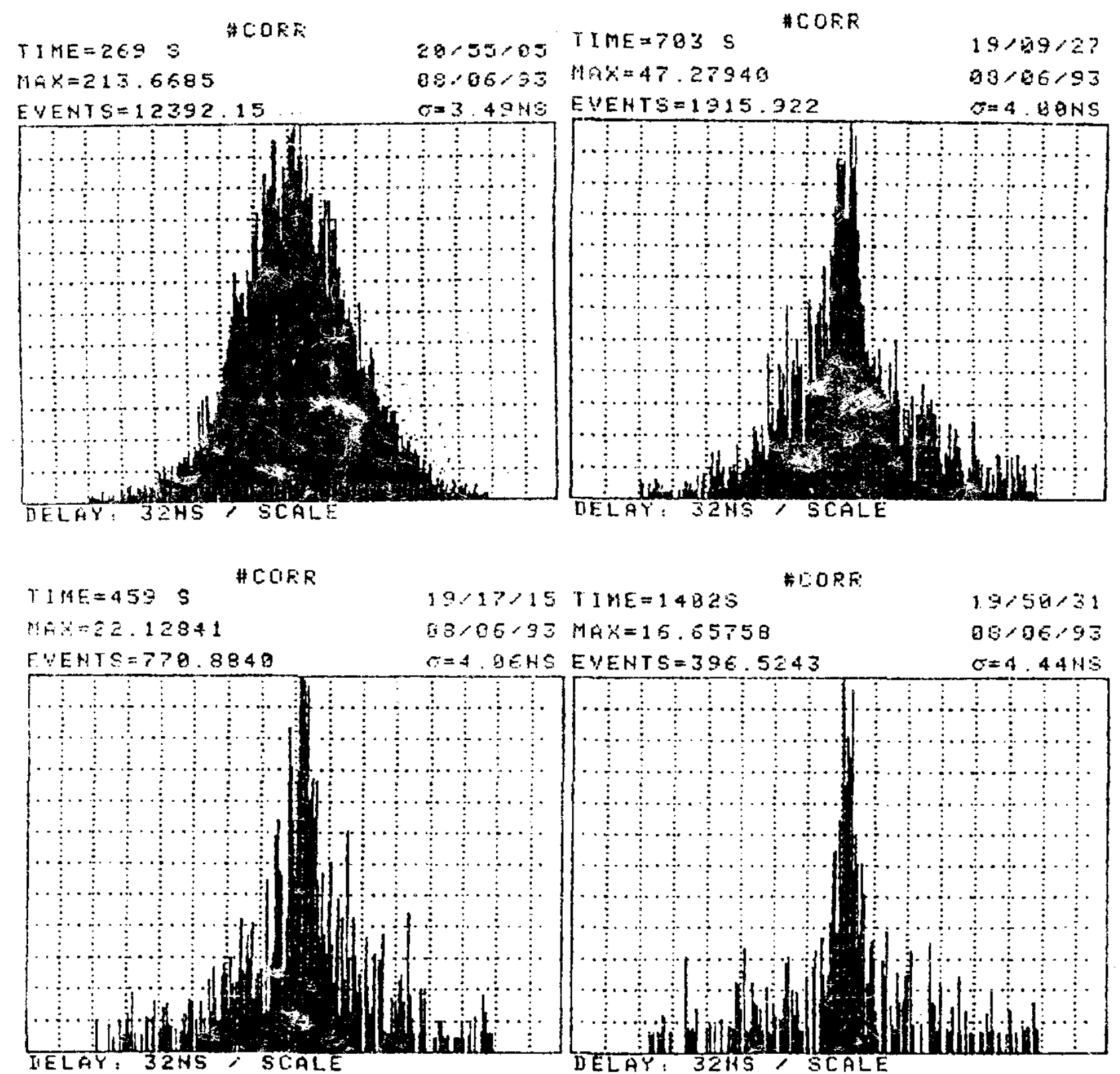

Fig. 5. The dependance of the number of photocount pairs from time interval between photocounts for the short electron bunch (150 ps). 

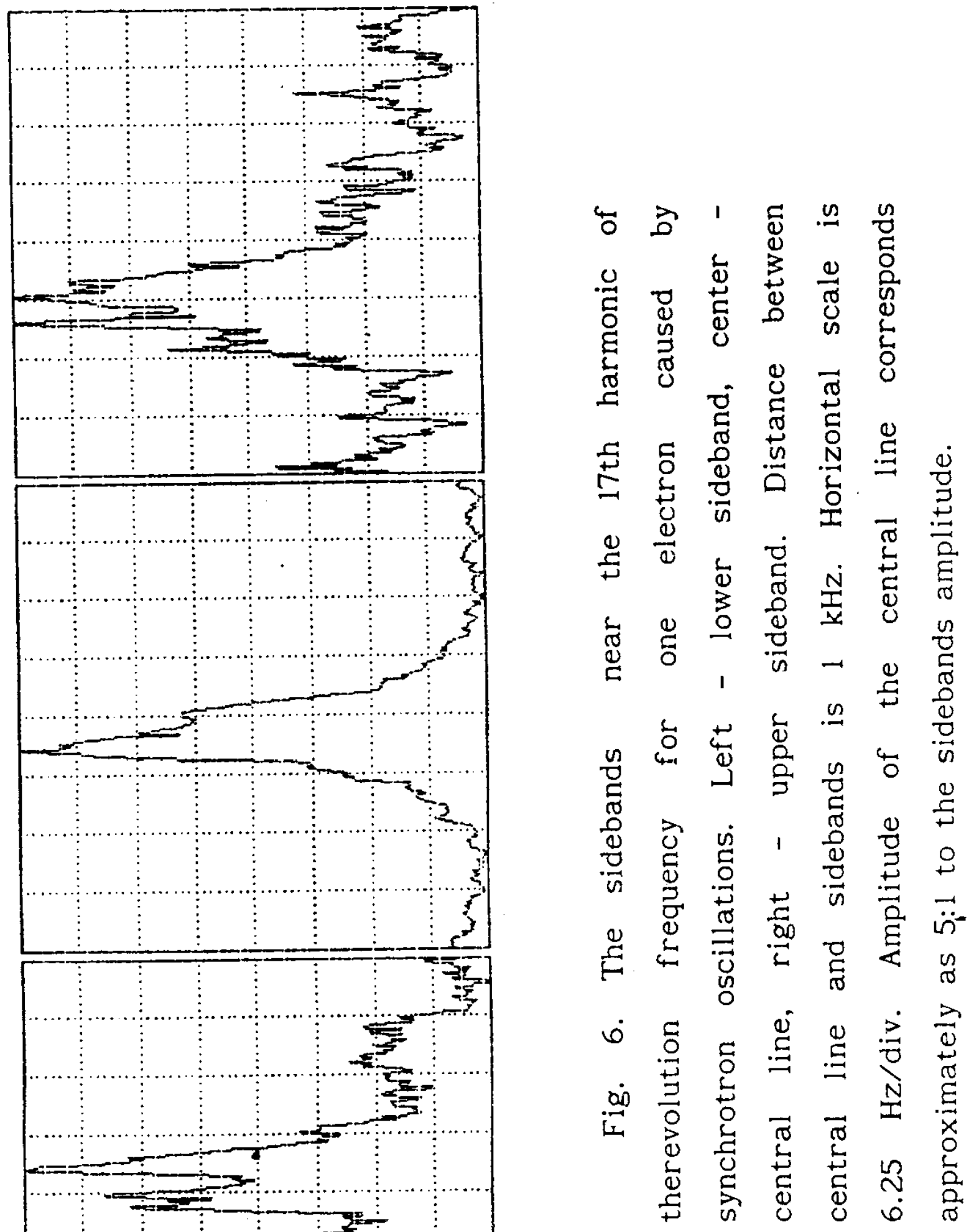
I.V. Pinayev, V.M. Popik, T.V. Shaflan, A.S. Sokalov, N.A. Vinokurov, P.V. Vorobyov

Experinents with Undulator Radiation of a Single Electron

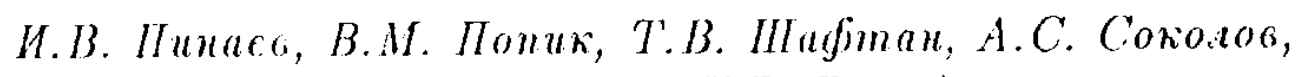
II.A. Вииокуров, ПТ.В. Воробье

Экиерименты с ондуляторным излученисм от отдельного электрона

Pañona noctynuta 8 centrópя $1993 \mathrm{r}$.

Hодинсано в печать $10.09 .19993 \mathrm{r}$.

Формат бумати $60 \times 901 / 16$ Объем 1,1 печ.л., 0,9 уч.-

Тираж 200 экз. Беспзатно. Заказ $\mathrm{N}^{0} 73$

Oópaботано на 1BМ PC и отпечатано на ротапритте ИЯа пм. Г.И. Будкера СО РАII, Новосибирск, 630090, пр. акаденика JIавреитьева, 11. 


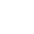

